\title{
Cardiac Defibrillator Issue
}

National Cancer Institute

\section{Source}

National Cancer Institute. Cardiac Defibrillator Issue. NCI Thesaurus. Code C99922.

The cardiac lead is not performing as expected with issues such as oversensing with or without shock or ATP, or failed shocks or inadequate DFT safety margins defibrillation activity. (ACC) 